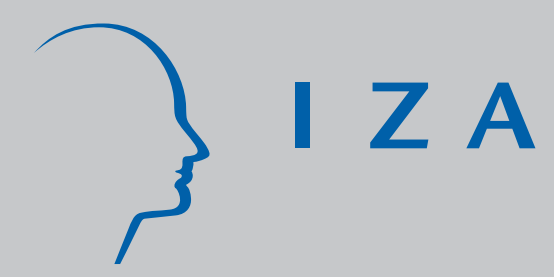

IZA DP No. 3057

Who Gives for Overseas Development?

John Micklewright

Sylke V. Schnepf

September 2007 


\title{
Who Gives for Overseas Development?
}

\author{
John Micklewright \\ S3RI, University of Southampton \\ and IZA \\ Sylke V. Schnepf \\ S3RI, University of Southampton \\ and IZA
}

\section{Discussion Paper No. 3057 \\ September 2007}

\author{
IZA \\ P.O. Box 7240 \\ 53072 Bonn \\ Germany \\ Phone: +49-228-3894-0 \\ Fax: +49-228-3894-180 \\ E-mail: iza@iza.org
}

\begin{abstract}
Any opinions expressed here are those of the author(s) and not those of the institute. Research disseminated by IZA may include views on policy, but the institute itself takes no institutional policy positions.
\end{abstract}

The Institute for the Study of Labor (IZA) in Bonn is a local and virtual international research center and a place of communication between science, politics and business. IZA is an independent nonprofit company supported by Deutsche Post World Net. The center is associated with the University of Bonn and offers a stimulating research environment through its research networks, research support, and visitors and doctoral programs. IZA engages in (i) original and internationally competitive research in all fields of labor economics, (ii) development of policy concepts, and (iii) dissemination of research results and concepts to the interested public.

IZA Discussion Papers often represent preliminary work and are circulated to encourage discussion. Citation of such a paper should account for its provisional character. A revised version may be available directly from the author. 


\section{ABSTRACT}

\section{Who Gives for Overseas Development?*}

Individuals' donations to overseas charities are an important source of funding for development assistance from rich industrialised countries. But little is known about the nature of these charitable donations. The literature on giving focuses on total donations to all causes and does not identify separately the pattern or the determinants of giving to any particular cause. We investigate giving to overseas causes using UK survey microdata that record individuals' donations to different types of charity. We establish a picture of overseas giving, comparing this with giving to other causes. Socio-economic correlates of both types of giving are analysed, including gender, marital status, occupation, education and, especially, income. We also investigate the relationship between individuals' overseas giving and their attitudes towards poverty in developing countries.

JEL Classification: D12, D64, F35, L31

Keywords: charitable donations, overseas development, NGOs

Corresponding author:

John Micklewright

School of Social Sciences

University of Southampton

Highfield

Southampton SO17 1BJ

United Kingdom

E-mail:jm4@soton.ac.uk

\footnotetext{
* This research was supported by ESRC project grant 'Giving to Development' (RES-155-25-0061), which forms part of the Non-Governmental Public Action programme. We thank our project colleagues Tony Atkinson and Cathy Pharoah for their very useful suggestions, the Charities Aid Foundation and the National Council for Voluntary Organisations for access to the data on charitable donations from the ONS Omnibus survey, and Charles Lound of ONS for clarification of the survey stratification and clustering. Useful comments were made by seminar and conference participants at University College Dublin, the ESRC WeD Group at Bath, the Voluntary Sector Studies Network, and the Royal Statistical Society.
} 


\section{Introduction}

Donations to charities working for overseas causes are an important source of funding of development assistance from rich industrialised countries. In the UK, charities focusing on overseas development and emergency relief that are among the top 500 fundraisers received nearly $£ 1$ bn in donations and legacies in 2004-5. This is well short of the $£ 4$ bn that is spent by the UK government in official development assistance (ODA) but the public appears to allot greater importance to the charities' work. ${ }^{1}$ Two-thirds of UK adults believe that international charities make a 'major contribution' to the reduction of poverty in developing countries while less than a fifth view the governments of rich countries in the same light (O’Brien 2004: 49).

Surprisingly, in view of their actual and perceived importance, relatively little is known about the pattern or determinants of charitable donations to development causes. There are large empirical and theoretical literatures on charitable giving but they focus on total donations, and in general do not identify separately giving by cause. Donations to overseas charities made up only 18 percent of all donations to the top 500 fundraising charities in the UK in 2004-5. The motives for giving to benefit human welfare in poor countries may differ in a variety of ways from those that drive giving to domestic causes such as animal welfare, health or the arts (Micklewright and Wright 2004, Atkinson 2007). If further charitable donations are to contribute to the funding of the Millennium Development Goals, then more information is needed about their determinants. We need to know whether and how giving to development differs from giving to other causes, and how, for example, overseas giving varies with income. In this paper we investigate giving using UK survey microdata that do record individuals' donations to different types of charity. We aim to discover stylised facts about giving to overseas development, showing ways in which overseas giving resembles giving to other causes and ways in which it differs. In doing so we provide new information on patterns of giving to all causes.

Section 2 describes the data we use and the problems of measurement of charitable giving. The data are drawn from several rounds of the ONS Omnibus Survey, which since 2004/5 has contained a module of questions on charitable giving

\footnotetext{
${ }^{1}$ The totals are taken from Charities Aid Foundation (2006) and HM Treasury (2004). The Charities Aid Foundation figures refer to all 'voluntary income', including legacies and donations by trusts and companies. But the great bulk represents inter-vivos donations by private individuals.
} 
sponsored by the Charities Aid Foundation (CAF) and the National Council for Voluntary Organisations (NCVO). Section 3 documents how common is giving to development and the amounts given, contrasting the situation with giving to other, or 'domestic', causes, and exploring the differences by gender, marital status, occupation and education. We also investigate whether giving to overseas and domestic causes tend to go together, or whether people making overseas donations are a quite separate group. Section 4 compares people's attitudes to poverty in developing countries and its relief with their actual giving to overseas causes. Are those who do not give unconcerned about the plight of poor countries or do they show their concern in ways other than charitable giving? Section 5 investigates the relationship of giving to overseas and to domestic causes with personal income. Do those on higher incomes give a greater share of their income to charity or is giving regressive, with the shares being higher for those on lower incomes? And how does the picture differ for overseas giving? Section 6 concludes.

\section{Data on charitable giving by cause}

Empirical research into the pattern and correlates of giving by cause has been hampered by a lack of survey data that identify the different causes to which donations are made. In the UK, the annual ONS Expenditure and Food Survey (EFS) and its forerunner the Family Expenditure Survey (FES) have long collected data on charitable giving. These have been used to good effect (e.g. Jones and Posnett 1991, Banks and Tanner 1997, Pharoah and Tanner 1997). But the survey does not distinguish the types of charities to which the gifts are made. ${ }^{2}$

Our research uses data from another ONS survey, the monthly Omnibus, that does collect information on donations by cause. Starting in 2004/5, CAF and NCVO have sponsored a module of questions in the survey three times a year (CAF and NCVO 2005, 2006). The Omnibus survey has a conventional multi-stage random probability design. ${ }^{3}$ One adult (defined as age 16 or over) is selected at random in

\footnotetext{
${ }^{2}$ Even in the USA, where the empirical literature on charitable giving is very well developed, the longrunning Michigan Panel Study of Income Dynamics has only recently begun to collect information on giving by cause (Backus 2006).

${ }^{3}$ The sample is stratified by region and by several measures of socio-economic status: the proportion of households with no car, the proportion of households where the household reference person is in the top three socio-economic categories in the ONS classification, and the proportion of people who are aged over 65 years. In common with other ONS surveys, the sample frame is the Royal Mail's Postcode
} 
each sampled household. Interviewing is face-to-face. The response rate is typically around 65 percent, which is reasonable by the standards of other ONS surveys, e.g. the EFS. We pool data for the six survey rounds in which the CAF/NCVO module was included in the survey in the April-March tax years 2004/5 and 2005/6: July (2004), June (2005), October and February (both tax years). This provides a sample of 9,050 individuals. ${ }^{4}$ The Appendix describes our cleaning of the amounts recorded in the data.

The CAF/NCVO module probes charitable giving in detail, seeking information on the amounts given and the methods of giving for donations to each of a range of causes in the four weeks prior to interview. People are asked whether they have given to charity through any of nine methods listed on a showcard. For each method used, respondents are asked which of 15 possible causes they have given to, of which 'Overseas aid and disaster relief' is one. Then, for each cause given to by each method, respondents are asked how much they gave. The design of the module was carefully chosen to provide greater detail and higher quality data than in previous efforts by CAF and NCVO to collect survey data on charitable giving. ${ }^{5}$

Although the months in which the data are collected are spread reasonably evenly through the year, there may still be problems of seasonality that affect what we can say. Suppose that there were a regular seasonal dip in charitable giving following Christmas. This would be reflected in the donations recorded in the four weeks prior to the February round of the Omnibus survey, and, since the CAF/NCVO module is included in the survey only three times a year, the pooled data would be disproportionately affected by this dip. Comic Relief, a large charity that spends 60 percent of its income overseas, gathers most of its donations through a 'telethon' and associated events in March, once every two years. ${ }^{6}$ Most of these donations will be missing from the data collected by the survey since the period concerned falls outside the survey months. And where donations to any charity are given by regular annual

\footnotetext{
Address File. Each survey cluster (which are postal sectors) contains 30 households and we allow for most of this clustering in our estimates of standard errors in our analysis (some clusters cannot be separately identified since IDs are not always unique across years).

${ }^{4}$ We apply weights that correct for the higher probability of being sampled in small households. The Omnibus sample size was reduced by about 30 percent in 2005 and we apply weights to ensure that each month of data contributes equally to the pooled sample.

${ }^{5}$ The CAF and NCVO use of the Omnibus survey replaces the Individual Giving Survey (IGS), which latterly formed part of an NOP Omnibus. The IGS was based on a quota sample rather than a survey with a random probability design and had a less detailed module on donations (see Lee et al. 1995).

${ }^{6}$ See http://www.comicrelief.com/all-about-us/faq/
} 
gifts (or membership subscriptions - see below) there will be the standard ‘infrequency of purchase’ problem suffered by budget surveys, with fewer donors recorded than would be the case if information on annual donations were collected.

The survey's restriction to one individual in each sampled household means that we cannot observe total of each houshold's donations. (Respondents are asked about their own donations but not those of other household members.) There is a potential problem of measurement of individual donations where married or cohabiting couples make decisions jointly about their charitable giving, funding their donations from their joint income. In this case, giving can be thought of as a public good within the household (Andreoni et al. 2003). An individual respondent may therefore lay claim to all the giving done by the couple. Although there would be no double-counting within surveyed households, since only one household member is interviewed, this situation would imply that aggregate amounts given are overestimated by the Omnibus survey. The survey does not collect any information on how couples make their decisions on donations, but we are able to distinguish separately the giving by people who are married or co-habiting and the giving by people who are single.

There are ambiguities in the concept of 'charitable giving' that must be addressed in any survey that collects data on donations (Lee et al. 1997). First, there is the definition of a charity. Not all voluntary organisations are charities, including some that may be perceived by the public as being so. Several organisations with charitable aims decline to seek charitable status since they feel it would restrict their ability to campaign as a pressure group. Amnesty International is an example. Other organisations are formal charities despite not obviously existing to provide benefit that is charitable in the public perception. This is illustrated by the recent debate in the UK on the charitable status of private schools. The CAF/NCVO module in the Omnibus survey in effect allows the respondent to decide whether a gift was to a charity or not.

Second, there is the concept of a gift. Giving may take various forms, and one important method, the donation of time or 'volunteering', is not considered in this paper (nor is it covered in the Omnibus survey): we are concerned only with gifts of money. But even here there is room for different interpretations. Lee et al. draw attention to the status of membership subscriptions to charitable organisations (e.g. to the National Trust or the Royal Society for the Protection of Birds), ticket purchases 
in raffles on behalf of charities, and purchases at charitable shops (1997: 41). These are three of the nine methods covered by the CAF/NCVO module, which also includes fundraising events (e.g. purchases or entrance fees to jumble sales, fêtes and charity dinners). ${ }^{7}$ In each case the respondent is asked for the full amount paid or transferred, all of which is treated as a donation. The survey therefore casts its net wide, although data for donations by each method are separately recorded so the user can choose to focus on a sub-set.

The different charitable causes identified in the Omnibus survey are listed in Table 1. Several points about the definition of overseas donations need to be borne in mind.

First, the inclusion of disaster relief in 'Overseas', which is standard for such classifications, means that the data for giving in each Omnibus round will be affected by any recent large international emergencies. The Asian Tsunami at the end of 2004 is the most obvious case. This disaster occurred shortly before the Omnibus round in February 2005, and the CAF/NCVO module for that month was adjusted to include giving for Tsunami relief as a separate additional category of donations in the four weeks prior to interview. A further question was also included to cover all giving to the Tsunami appeal since the tidal wave struck on 26 December. The earthquake in Pakistan in early October 2005 is another example of a large emergency appeal, although in this case the CAF/NCVO module that month did not identify donations for the earthquake victims' relief as a separate cause. We do not include the February 2005 data on giving for the Tsunami appeal in our analysis, treating it as an exceptional episode - see the Appendix.

Second, giving to overseas causes does not necessarily imply giving for the benefit of people in poor countries. For example, donations to charitable causes in Israel would presumably be included by Omnibus respondents under the 'Overseas' heading. However, in the UK, the great majority of overseas giving is in fact aimed at poor countries. ${ }^{8}$ It is also the case that some charities have both domestic as well as overseas aims, and have significant programme expenditure in the UK. The Red

\footnotetext{
${ }^{7}$ The other five are cash, card/cheque, direct debit, payroll giving, and 'other'. Purchases at charity shops is included in 'buying', which also covers purchases through charity catalogues and buying the Big Issue. The values of gifts that an individual may have made to charity shops, jumble sales, or for charity raffles are explicitly excluded by the survey.

${ }^{8}$ For example, among the top 500 fundraising charities classified by CAF as 'overseas', only 5 percent of voluntary income is received by charities devoted to Jewish causes outside the UK, including those not focused on charitable work in Israel.
} 
Cross, which is explicitly mentioned in guidance to Omnibus interviewers as an example of an overseas charity, falls into this category.

Third, some respondents may report donations for development under another heading. Is a donation to Save the Children or to UNICEF one that benefits an overseas cause or one that benefits children? Do donations to the Catholic Agency for Overseas Development (CAFOD), to Christian Aid, or to Islamic Relief represent giving to development or giving to a religious organisation? The CAF classification of top 500 fundraising charities in Charity Trends treats all these as overseas charities. Our presumption is that respondents to the Omnibus survey will also do so, but it is difficult to rule out all such problems of classification in respondents' minds.

The core questionnaire included every month in the Omnibus survey collects a range of demographic and socio-economic information that we use to analyse the correlates of giving, including age, marital status, number of children, household composition, education, occupation and personal income. These characteristics are likely to be correlated with attitudes towards giving to different causes, including overseas development and disaster relief. For one month in the pooled data set, July 2004, we have direct information about respondents' attitudes towards development that we can link to their giving behaviour. The Omnibus survey in this month included a module of questions sponsored by the Department for International Development (DfID). This collected information on respondents' attitudes towards poverty in developing countries and towards the roles of international charities, governments and international organisations in its reduction. (The data are the basis for the figures on public attitudes cited in the opening paragraph of the Introduction.).

\section{Giving to overseas and to domestic causes}

Table 1 shows the percentages of persons in our pooled sample giving to each of the causes identified in the CAF/NCVO module, together with the mean and median amounts given. Just over half the sample gave to at least one cause in the four weeks prior to interview and the amounts given to all causes taken together averaged nearly $£ 27$ per donor.

What about development? 1 in 10 persons gave to overseas aid and disaster relief. Only medical research, children/young people, and hospitals/hospices attract more donors than overseas causes. And only religious organisations have both higher 
mean and median amounts. (The high mean for the arts is subject to very large sampling error, being based on only 47 donors.) Overseas charities’ position as a leading cause stems from both the high frequency of giving and the large average amounts donated relative to other causes - something not shown in aggregate statistics on the charitable sector. Both the frequency and the average are ahead of the figures for animal welfare, the cause often cited in the popular press as the most popular target for charitable donations in the UK. The overseas mean is nearly threequarters of that for all domestic causes taken together and the medians are even closer, underlining how big the size of overseas donations are in relative terms.

For all causes, including overseas, the distributions of the amounts given show very high positive skew: the means are far higher than the medians, often by a factor of more than 2. The well-known skew of household incomes is much less: mean UK weekly household income is less than $1 \frac{1 / 4}{4}$ times the median. ${ }^{9}$ Table 2 gives more information on the distributions for overseas and other leading causes. A half of all donors provide about 90 percent of all overseas donations; and a half of all overseas donations are given by only 1 in 10 donors. These figures differ somewhat for other causes, but sampling variation means that not too much should be read into the differences. ${ }^{10}$ When allowing for the frequency of giving in Table 1 , this pattern means that a half of all overseas donations are made by only 1 percent of the adult population.

These figures relate to donations in the four weeks prior to interview. The skew in the distributions of annual donations can be expected to be less. More people almost certainly give over the course of a year than in one month and the annual distributions would be less affected by one-off large gifts recorded for a few people in the monthly figures - the problem of 'infrequency of purchase' referred to earlier. On the other hand, our cleaning of the Omnibus data may have led to the skew in the monthly distributions being underestimated. A less conservative approach to cleaning would lead to the positive skew being even higher - see the Appendix. Results are quite sensitive to the treatment of the few very large gifts recorded in the data.

\footnotetext{
${ }^{9}$ Department for Work and Pensions, Households Below Average Income 2005/06, Figure 2.1 (http://www.dwp.gov.uk/asd/hbai/hbai2006/pdf_files/chapters/chapter_2_hbai07.pdf). The figures refer to equivalised net household income before housing costs.

${ }^{10}$ The sample sizes for the top 10 percent of donors in Table 2 ranges across the causes from 60 to 190 persons.
} 
It is a common belief that women give more to charity than men. CAF and NCVO's own analysis of the Omnibus data show that it is indeed the case that more women make donations, but the average amount given per donor is higher for men (CAF and NCVO 2006: Table 3). Does this picture hold for overseas giving? In view of the uncertainty surrounding responses of couples to the survey, Table 3 shows figures separately for married and cohabiting people and people who are single. (For brevity, we include cohabitees among 'married' in the rest of the paper.) As with all domestic causes taken together, more women give to overseas causes than do men. In fact this is also true of almost all other causes when taken individually (not shown in the table). Only sports, the arts, and the residual 'other causes' category attract more men than women. And the higher frequency of giving among women is found for both single and married respondents. The higher figures for married people are consistent with donations being a public good within marriage (leading each partner to be more likely to report giving), but other explanations based on systematic differences between single and married people could also explain this pattern.

What of the amounts given? For domestic causes, the pattern of the means per donor reflect the CAF/NCVO findings of higher amounts for men (which were based on only three waves of data), although the difference is not statistically significant for single people. For overseas giving however, we cannot reject the hypothesis that the means for men and women are the same. The comparison of means is strongly influenced by high values right at the top of the male distribution. The medians, which are not affected by outliers, give a mixed picture - for single people the female figures are higher. The mean donations per head, which take account of both frequency of giving and amounts given, are generally higher for women, although none of the differences from the male figures are statistically significant. ${ }^{11}$

The literature from both the USA and the UK has shown occupation and education to be important correlates of giving (Jencks 1987, Banks and Tanner 1997, Havens et al. 2006). Table 4 investigates how these and a number of other socioeconomic characteristics are associated with differences in overseas and several types of domestic giving. People with a managerial or professional backgrounds are over twice as likely to give to overseas as a routine or manual worker, a differential that is notably larger than for the other causes. The change in giving to overseas with

\footnotetext{
${ }^{11}$ Gender differences in giving recorded in the Omnibus data are considered in detail by Piper and Schnepf (2007).
} 
increased education is also greater. By contrast, giving to medical research and, especially, animal welfare varies little with any of the characteristics in the table. The elderly are slightly less likely to give to all the causes illustrated. Giving to child welfare is notably more common among those with dependent children. Owneroccupation, a proxy for wealth, is associated with only a slightly higher frequency of giving compared to the average person, with the difference varying little across the causes. (The relationship of giving with income is considered later in the paper.)

In theory, people giving to development might be a completely separate group from those giving to domestic causes. But Table 4 suggests that this is not the case in practice. For example, higher levels of occupation and education are associated both with giving to overseas and to domestic causes, albeit to a different extent. Table 5 shows that three-quarters of overseas donors also give to at least one domestic cause. ${ }^{12}$ In other words, the probability of giving to domestic causes, conditional on being an overseas donor, is higher than the unconditional probability of domestic giving ( 0.74 compared to 0.53$).{ }^{13} \mathrm{~A}$ half of overseas donors give to two or more other causes and nearly a third to three or more (this is not shown in the table). These figures turn out to be very similar to the average pattern for other major causes. Many people spread their charitable giving.

Further analysis reveals that overseas donors have a higher probability of giving to each and every one of the 14 separate domestic causes in the data than does the sample as a whole. Conservation and the environment, religious organisations, arts, and the homeless attract disproportionate numbers of overseas donors: in each case they are over $2 \frac{1}{2}$ times more likely to give to the cause in question than the average person. ${ }^{14}$ Or, restricting the comparison just to people who do give to charity, they are about $1 \frac{1}{2}$ times more likely to give to these causes than the average donor.

However, the clustering of overseas giving with other giving is not unique; whatever cause we consider, the data show that the probability of a donor to that cause giving to one of the other 14 causes in the data is higher than the unconditional probability of giving to the other cause. In broad terms, giving to one charitable cause

\footnotetext{
${ }^{12}$ We use the term 'overseas donor' in the rest of the paper as a shorthand for people making donations to overseas causes.

${ }^{13} 0.74=7.7 / 10.4$.

${ }^{14}$ The amounts given to overseas causes are also in each case positively correlated with the amounts given to the domestic causes (although the correlations are often quite low).
} 
tends to go hand in hand with giving to other causes, not withstanding the differences we have emphasised from Table $4 .^{15}$

With most causes the clustering is in fact higher than it is for overseas giving. The figure of 26 percent for the percentage of overseas donors who give just to that cause is surpassed only by the percentages for giving to children (27 percent), medical research (32 percent) and 'other' (38 percent). Children and medical research, like overseas, are among the most popular causes. It is for the less popular causes, e.g. arts, sports, and conservation, where clustering is greatest and where the percentage of ‘unique’ donors to that particular cause is lowest.

\section{Who cares about overseas causes but does not give?}

It is tempting to see Table 5 as confirming the old adage that 'charity begins at home'. Many people give to domestic causes. But the great majority of people do not make overseas donations. And among those that do, most are also giving to domestic causes as well. ${ }^{16}$

But there is evidence that many of those who make only domestic donations, or who do not give to charity at all, are not indifferent to the plight of people in developing countries. The Appendix describes the widespread response following the Asian Tsunami in December 2004 - about two-thirds of all adults contributed although we also argue this to be an exceptional event. This section draws on other evidence, contained in the July 2004 DfID module in the Omnibus survey that was described at the end of Section 2. The information collected offers a great opportunity to probe beneath the recorded giving and to learn more about motives.

Table 6 classifies responses to a question on concern about levels of poverty in developing countries against donor status recorded in the CAF/NCVO module that was also in the questionnaire that month. The great majority of overseas donors reported that they were 'concerned' or 'very concerned'. (That 1 in 10 did not express

\footnotetext{
${ }^{15}$ In part, the patterns in the data may reflect problems in their collection. Imagine a peron gives to Christian Aid and Oxfam and despite the conventional classification being that both these are overseas causes, reports the Christian Aid gift as a donation to a religious cause. Then this 'mis-reporting' (according to the convention) leads to clustering of the two causes in the data. But it seems impossible that the patterns reflect only this form of explanation. Many causes are fairly clear-cut, e.g. animal welfare, sport or medical research.

${ }^{16}$ We can in fact infer nothing from the data about the prioritising of different causes by people who make overseas donations. They may see overseas giving as an essential part of their altruism that comes first in their decision making. Their domestic giving may be 'added-on' to their overseas giving.
} 
any concern is clearly surprising.) But the same applies to the majority of most other people: 72 percent of those giving to domestic causes only and 63 percent of nondonors, although many fewer were 'very concerned' than among the overseas donors.

This suggests that there is considerable potential for expansion of overseas giving. Who are the people who express concern about poverty in developing countries but do not give? Some may be people who have an annual direct debit to an overseas charity which did not fall due in the four weeks prior to interview, the period covered by the questions on giving. This is the 'infrequency of purchase' problem discussed earlier. But there are also systematic differences between the 'caring donors' and the 'caring non-donors'. Table 7 shows the percentages of people of different characteristics who 'care’ (i.e. are concerned or very concerned about developing world poverty) and, among those who do care, the percentages who then actually give to overseas causes. In this way we delve beneath the surface of the patterns of overseas giving shown earlier in Table 4 (although the data in Table 7 refer to only one survey round). For example, we see that the positive association of degree level education with overseas donations reflects both a higher probability of caring about developing world poverty and a higher probability of actually making a donation given that one cares. (This is seen by comparing the figures for 'degree' with those for 'all persons'.) It is still the case however that three-quarters of people with degrees who care are not recorded as giving. The same pattern is found for managers/professionals, while those with only O-level or GCSE qualifications are both less likely to care and less likely to make a donation given that they do care. On the other hand, women have a higher probability of caring but their probability of giving if they do care is little different from the average.

Another explanation for caring but not giving is that a person may favour other methods of helping the poor in developing countries. The DfID Omnibus survey module asks respondents about the ways they think they could, as individuals, 'most effectively contribute to the reduction of poverty in developing countries'. Table 8 shows the percentages of persons mentioning different methods among the maximum of up to three that may be given (the methods were presented to repondents on a showcard). We restrict attention again to those persons expressing concern about developing country poverty.

It is striking that charitable giving comes top irrespective of donor status. It is not the case that giving is viewed as ineffective by those who do not make overseas 
donations. And in general it is the similarities rather than the differences between the sets of figures for the three groups that is perhaps most striking. People making only domestic donations or those not giving at all are somewhat more likely to cite paying taxes but the differences are not great. ${ }^{17}$ Further analysis (not shown) reveals women in all three groups to be more likely than men to cite buying fair trade goods, involvement in the church, and (except among overseas donors) making charitable donations. Overall these results can be seen as encouraging for international charities: charitable giving finds very widespread support, including among those not currently giving.

\section{Income and charitable donations}

If overseas donations increase more than proportionately as income rises, then higher real incomes over time will produce disproportionately large increases in charitable giving. In this case, overseas giving is classified as a luxury in economic terms. If, on the other hand, overseas giving rises less than proportionately, then it is a necessity. The growth in overseas donations over time would lag behind growth in incomes. In both cases the funding of the Millennium Development Goals is helped but the funding benefits much more if overseas giving is a luxury.

The future path of overseas donations provides one motivation for investigating the link between donations and income. Another comes from contrasting the incidence of taxation to fund government spending on ODA with the incidence of private individuals' overseas giving. The overall tax burden is progressive, the rich paying a higher proportion of their income in tax than the poor (e.g. Jones 2006). But if charitable donations to overseas causes are a necessity, as just defined, then by contrast they are regressive: the share of income given falls as income rises. This type of comparison may seem invalid; donations are voluntary while taxes are obligatory. However, the concept of a tithe (a tax levied by a church on its members and a traditional feature of several religions) suggests that this comparison is not unnatural. Tithes to fund good works are typically proportional - a constant share of income - or

\footnotetext{
${ }^{17}$ We cannot rule out that this pattern results from those not making overseas donations feeling the need to justify that behaviour by citing their taxes as important. The credibility of responses is also questioned by qualitative research that shows considerable scepticism about the effectiveness of taxfinanced Official Development Assistance (Atkinson and Eastwood 2007). (This research is another part of our ESRC-financed project.)
} 
mildly progressive (achieved through a tithe-free allowance followed by a constant marginal rate). They are not regressive. An analogy may also be made with the voluntary participation in the UK National Lottery. One of the concerns with the Lottery is that it is regressive - the good causes that the lottery contributes to are disproportionately funded by the gambling of low income people.

The existing UK literature on the relationship of giving to income is sparse, even if we restrict attention to total donations. The standard reference is Banks and Tanner’s (1997) analysis of Family Expenditure Survey (FES). Using 1993-4 data, they found the share of total household expenditure going on charitable donations to all causes to fall from about $2 \frac{1}{2} 2$ percent for the bottom 20 percent of households, ranked by total income, to less than one percent for the $8^{\text {th }}$ and $9^{\text {th }}$ deciles, before rising slightly to just over one percent for the top 10 percent of households (Banks and Tanner 1997, Figure 2.4). However, these figures refer only to those households that do actually give - they show how the share given varies for donor households only. In addition, Banks and Tanner found that the proportion of households making donations rose notably with income, from about 15 percent for the bottom fifth to over 40 percent for the top fifth (ibid, Figure 2.3). Regression models both for the probability of giving and for amounts given, controlling for other factors, were also estimated. The results implied that, holding other factors constant, donations are (just) a luxury. ${ }^{18}$ The much larger US literature is reviewed by Havens et al (2006) who argue that contrary to popular belief, a reverse J-shaped relationship of a falling and then slightly rising income share (suggested also by Banks and Tanner's descriptive evidence for donor households) does not hold. They argue that the income share changes little across the income distribution, before rising sharply at very high income levels (around \$300,000 pa).

The UK literature is almost silent on how donations to overseas causes varies with income. The notion that 'charity begins at home' suggests that overseas giving is a luxury and hence progressive in incidence: people give mainly to domestic causes at lower levels of income but add-on giving to overseas causes as their income rises. This would be consistent with Jencks' suggestion that people both 'pay their dues'

\footnotetext{
${ }^{18}$ Both the probability of giving and the (log) amounts given by donors were modelled as functions of (log) income, with the estimated income parameters highly significant. The elasticity of donations, D, with respect to income is the sum of the separate elasticities of the probability of giving, P, and of the amounts given by donors, $G$ (where $D=P$.G). The regression models were estimated for a dataset pooled from 1984-94, covering more than 70,000 households.
} 
and 'give away surplus' (1987: 324). Breeze's novel (2006) study does explore the relationship between giving by cause and income. She argues that the J-shaped relationship referred to above applies to all causes. However, the data refer to a purposive sample of current donors known to several major charities. By contrast, the Omnibus survey has a random probability design that generates a sample representative of the population as a whole, including of course both non-donors as well as donors.

In building on the existing results, we need to recognise that the Omnibus data on both giving and income differ markedly from what is available in the FES or its successor, the EFS. The Omnibus survey has a broader definition of a gift and covers giving over a longer period (the expenditure diary in the EFS covers only two weeks). And it records the individual giving of one person per household rather than household giving, although we have noted that the two might be the same for couples due to the public good nature of donations. The survey also provides information only on individuals' own incomes, and not on the incomes of people they may live with. Hence we can relate individual giving to individual income, but not household giving to household income. For someone in a couple, individual income may not be a good indication of access to resources from which to make donations. If couples pool their income, the partner with lower income will be able to fund more donations than can a single person with the same personal income. We may find sizeable donations made by people with virtually no personal income of their own. For these reasons we focus in particular on the results for single people.

It is also the case that the Omnibus survey's data on income are much less detailed than those from the FES, where respondents are asked for exact amounts from each separate source. The Omnibus survey contains a single question that asks respondents to indicate from a list the band of annual income containing their gross income from all sources. There are 33 bands in the 2004/5 data (including zero income) and 39 bands in 2005/6, the highest being $£ 52,000$ or more (which contains only 3 percent of people providing data on income). About 8 percent of people in our pooled sample declined to respond to the income question and they are excluded from the analysis of this section. The distribution of individual income in the Omnibus survey in fact corresponds reasonably well with those in both the EFS and the Family Resources Survey (FRS), although there is some indication that income is understated by women (Micklewright and Schnepf 2007). Using FRS data, we also show that 
many women with low personal income live in households with much higher income per adult. For example, among women with less than $£ 2,500$ of gross personal annual income in 2004/05 - about 1 in 10 of all women - about a half are in households where income per adult is $£ 10,000$ or more. Finally, the limits of our sample size and the lack of detail for high incomes means that we can say nothing about the donations of the very rich (see e.g. Lloyd 2004). The upturn in any 'J-shaped' relationship may simply not be covered by our data.

Figure 1 shows how the percentage of people giving to overseas causes changes across the income bands, expressed in monthly terms. We compare these figures with those for all domestic causes taken together (turning later in the section to look at several different causes separately). The percentages giving are plotted against the mid-points of the relevant bands. For the top open-ended band we use the mean of gross individual income in the 2004/5 Family Resources Survey. Several data points are based on only small sample sizes, entailing high sampling error, and it is the general patterns in the data that should be the focus rather than particular values. ${ }^{19}$ The frequency of both overseas and domestic giving rises with income for single people. Around 10 percent of single people make overseas donations in the lowest income bands, the figure then falling somewhat before rising to levels of 15-20 percent at incomes of $£ 1,500$ per month or more. The rise is clearer for domestic giving, although the proportional rise is in fact not dissimilar to that for overseas giving in the bottom half of the distribution - the percentage rises by a factor of about 1.5 to about 60 percent at levels of about $£ 1,700$ or more. For both overseas and domestic giving there seems to be a flattening out of the relationship with income at high levels. (In the case of domestic giving this has to be the case, since the percentage giving cannot rise above 100 percent.) The lower half of the figure shows the picture for married people. This is quite different, especially at low incomes and especially for domestic giving where the relationship appears fairly flat.

In Figure 1 we do not distinguish differences between men and women but in Figure A1 in the Appendix this distinction is made. It also presents the data in a different way, by plotting the percentages against quintile groups of income rather than income levels. The rise in giving with income is steeper for single women than

\footnotetext{
${ }^{19}$ Due to small cell counts, persons in the three intervals that span annual incomes from (over) $£ 0$ to $£ 1,559$ were attributed to $£ 780$, persons in the two intervals spanning $£ 1,560$ to $£ 2,599$ were attributed to $£ 2,080$, and persons in the two intervals from $£ 12,480$ to $£ 14,559$ were attributed to $£ 13,520$. For 2005/06 data, persons in the six intervals spanning £36,400 to £51,999 were attributed to £44,200.
} 
for single men. The pattern for married and single men appears fairly similar, but this is not the case for married and single women, especially for domestic giving. The apparent steady rise in domestic giving across income groups does not imply that the marginal propensity to give is constant across income levels. Indeed, it falls as income rises (as shown in Figure 1), since successive quintile groups represent wider bands of income.

Figure 2 plots the mean donations per head against income, obtained by multiplying the frequencies in Figure 1 (expressed as proportions rather than percentages) by the mean donations per donor in each income band. The data are plotted on log scales. This makes it easier to compare the proportional changes for overseas giving and domestic giving and hence to judge whether the former is more or less responsive to changes in income. The proportional changes are also the basis for the classification of the two types of giving as luxuries or necessities in economic terms. The line drawn on the diagrams shows the case where the donations represent one percent of monthly income. In this case, where the share of income given to charity is constant, donations rise hand-in-hand with income, i.e. a 10 percent rise in income leads to a 10 percent rise in donations. The same is true of any other line that could be drawn which is parallel to the one percent share line: a constant share and an equi-proportional increase in income and donations. If the data points rise more steeply than the line on the diagram (or any parallel line) then the cause in question can be classified as a luxury (share rising with income); if they rise less steeply then giving is a necessity (share falling with income). In broad terms, if we set aside people with incomes below about $£ 250$ (about 1 in 5 of the sample), the two data series for single people appear roughly parallel to the line. A given percentage increase in income leads to about the same percentage increase for both overseas and domestic giving. This is the border between classifications as a luxury and as a necessity, or between donations being labelled as progressive or regressive. There is some suggestion that the data series for overseas giving rises slightly more steeply than that for domestic giving, where (bar the final point) the slope of the data appears slightly less than that of the one percent share line. But there is little in it. For married people, giving rises less than proportionately with income, and at lower levels does not rise at all, reflecting in part what was already seen in Figure 1.

Taking all married and single people together, one percent of income of monthly income is given to domestic causes and another one seventh of a percent to 
overseas causes. Table 9 summarises how these shares differ for people in the top fifth of the income distribution (with individual annual incomes of about $£ 20,000$ or more). ${ }^{20}$ The shares for married people are clearly lower in the top fifth for both causes, domestic and overseas, reflecting the pattern in Figure 2. This is particularly notable for women and especially for overseas giving. The situation is a very different for single men: the domestic giving share is slightly higher for the top fifth than for those on lower incomes while the overseas share is the same. Single women also have overseas giving shares that are essentially the same for the top fifth and for the other four-fifths, and domestic shares that differ little. Note that our income measure refers to gross income, before deductions due to tax and National Insurance contributions. If the data were to measure net incomes, after deductions, the shares in Table 9 would be higher. Moreover, since people with higher incomes pay higher taxes as a proportion of their income, the figures would rise more for the top quintile group. In the case of single people, the change could result in overseas giving appearing as a luxury in economic terms for both men and women, and the share for domestic giving for men appearing even higher for the top income group. ${ }^{21}$

Do the increases in charitable giving with income largely reflect the correlation of income with other factors that we have shown be positively associated with giving: occupation, education, and home ownership? We focus on single people for whom the interpretation of individual income is clearer and restrict attention to the probability of giving (leaving aside the amounts given). We also now compare overseas giving with several separate domestic causes. Table 10 shows the results of estimating logistic regression models of the probability of giving on the natural logarithm of income. ${ }^{22}$ We exclude from the regressions people with annual incomes below $£ 2,600$ in order to get a better fit of the model to the data. (We want only a simple specification for income.) We first include no controls for other factors and then see the impact on the income coefficients of including the controls (these include gender, which is negatively correlated with income).

\footnotetext{
${ }^{20}$ The shares are calculated for each group as a whole: total donations for the group are expressed as a percentage of the group's total income (including the income of non-donors).

${ }^{21}$ The values of the shares cannot be compared directly with those found by Banks and Tanner using the FES that were cited earlier due to the differences in measurement of both giving and income. The Banks and Tanner results also refer only to donors.

${ }^{22}$ We assign each individual to the mid-point of their income band. See the notes to Table 9 for the treatment of the top unbounded range. The logistic regression model specifies the probability of giving, $\mathrm{P}$, to be the function $1 /(1+\exp [-\mathbf{B} . \mathbf{X}])$ where $\mathbf{X}$ is a vector of explanatory variables and $\mathbf{B}$ is a vector of coefficients.
} 
With no controls, the coefficient for overseas giving and that for all domestic causes taken together are similar although the former is somewhat larger, reflecting the pattern described in Figure 1. But giving to medical research and, especially, animal welfare is less strongly associated with income. With the other factors controlled for, the most marked change is for overseas giving. The income coefficient falls sharply and becomes statistically insignificant at conventional levels. By contrast, it changes little for the other causes. ${ }^{23}$ The results for the control variables (not reported) confirm the strong impact of education on overseas giving that we highlighted earlier in Table 4, and in particular higher education. For the other causes, there is no significant difference in the probability of giving between persons with higher education and persons with no formal qualifications, once income and the other factors in the model are controlled for.

These results suggest that the recent expansion of higher education in the UK may be favourable for overseas giving, but they also warn against a simple view that rising real incomes will bring forth more donations. However, caution is needed here. Findings based on a cross-section survey that measures differences in income and education at one point in time may not be a reliable guide to the impact of changes over time.

\section{Conclusions}

We have established a picture of charitable giving to overseas causes and have shown whether this giving differs from that to other, 'domestic', causes. In doing so we have found out quite a bit more about patterns of charitable giving in general.

Overseas development and emergency relief is one of the leading charitable causes. We find this is due both to a relatively high frequency of giving compared to many other causes - 1 in 10 persons in the four weeks before interview - and high average amounts given by donors. The distribution of overseas giving is very highly skewed (far more so than household income), so that a half of all donations are given by the top 10 percent of donors, or 1 percent of the adult population.

\footnotetext{
${ }^{23}$ The estimated coefficient for domestic giving (all causes together) implies that for someone with a predicted probability of giving of 0.5 (about the sample average), a 10 percent rise in income increases the probability of giving by about 2 percent.
} 
The skew in the distribution of amounts given is one of the similarities that overseas donations share with giving to other causes. And people who are more likely to give to overseas causes are more likely to give to domestic causes as well: women, married people, and (in the case of several other leading causes) people with higher socio-economic backgrounds in terms of education and occupation. The relationship of giving with income seems similar for overseas donations and for donations to domestic causes - at least when the domestic causes are taken together. Focusing on single people, we find shares of gross income given to charity that are broadly constant (other than at lower levels of income). In crude terms, giving is distributionally neutral for large parts of the individual income distribution, neither progressive nor regressive. The similarities in characteristics of overseas and domestic donors means that most people who make overseas donations also give to domestic causes as well.

But there are also some clear differences between overseas and domestic giving, especially when we look at giving to particular domestic causes. Higher education and a managerial or professional background have a much stronger association with the probability of overseas giving than with giving to medical research and animal welfare for example. (Giving for animals varied little with individual characteristics.) When we control for other factors correlated with income, the income 'effect' on the probability of overseas giving drops away, in marked contrast to giving for children's charities, for example, and also all domestic causes taken together. Although overseas giving in general goes hand in hand with other giving, there are particular causes - for example conservation and the environment, and religious organisations - with which it is most associated.

The great majority of people do not give to overseas causes (at least over the four week period covered in the data), but most people do express concern over poverty in developing countries. And most people who do not make overseas donations report that they see charitable giving as an effective method by which they can contribute to the alleviation of this poverty - more so than for any other method. There is encouragement here for international charities' fundraising efforts.

Finally, we comment on the source we have used in the paper, the data collected through the CAF/NCVO module in the ONS Omnibus survey. This source marks a major step forward in information on charitable giving in the UK, and pooling the data for more than one year, as we have been able to do, increases what 
can be said about particular causes or particular groups of people. But there are features of the data that are not ideal. The classification of donations by cause is not certain. The information on giving for married couples is somewhat hard to interpret on account of the potential public good nature of giving within marriage. Even with two years of pooled data, sample sizes are small for some causes, for people on high incomes, and for people making large gifts (the marked skew in the distribution of giving highlights the importance of information on the latter). The survey provides a rather rough and ready measure of individual income, and household income is unobserved. Improvements to the CAF/NCVO questionnaire module may be possible. But, as an Omnibus, intended to obtain information 'on a variety of topics too brief to warrant a survey of their own' (ONS 2007), the survey can probably never give the detail that a dedicated survey of individual and household giving could provide. 


\section{Appendix}

\section{(i) Cleaning the Omnibus data}

We follow the cleaning rules established by CAF and NCVO for their analysis of the data in CAF and NCVO $(2005,2006)$. These rules set donations to zero if they exceed a level that varies with the method of giving, as follows (the number of gifts affected and the median values are shown in brackets): cash if $£ 200+(19, £ 500)$, fundraising events if $£ 500+(8, £ 800)$, payroll giving if $£ 100+(4, £ 118)$, direct debit if $£ 300+(10$, $£ 500)$, cheques if $£ 1,000+(6, £ 1000)$, raffle ticket purchases if $£ 100(2, £ 150)$, buying goods if $£ 200+(5, £ 200)$, membership fees and subscriptions if $£ 300+(1, £ 300)$, and other methods if $£ 1,500+(3, £ 20000)$. We refer below to these rules as the CAF/NCVO cleaning.

We experimented with two other sets of rules. First, we top-coded the amounts detected in the CAF/NCVO rules at the threshold levels indicated above. For example, a cash gift of $£ 300$ is set to $£ 200$. Second, we left the figures at the original amounts. With both these alternatives, however, we set two huge outliers to zero, one of $£ 20,000$ and one of $£ 100$ million (also set to zero in the CAF/NCVO rules). Table A1 shows the impact of these three alternative sets of rules on the mean amounts given and on the share of donations given by the top 10 percent of donors. (The mean per donor and the share of top 10 percent with the CAF/NCVO rules are those reported in Tables 1 and 2.)

The means and shares rise appreciably, with the effect of using the original amounts being particularly marked. There is also an impact on the shares of total gross income given by the top 20 percent and the bottom 80 percent of the income distribution (Table 10). For example, for single men the shares change from 0.77 and 0.82 percent to 0.83 and 1.12 per cent when we use the original amounts. The results underline the need for more detailed investigation at the top end of the distribution of donations. 
Table A1: Impact of alternative cleaning rules for large donations

\begin{tabular}{lcccccc} 
& \multicolumn{3}{c}{ All donations } & \multicolumn{3}{c}{ Overseas donations } \\
& $\begin{array}{l}\text { Mean per } \\
\text { donor }(£)\end{array}$ & $\begin{array}{c}\text { Mean per } \\
\text { head }(£)\end{array}$ & $\begin{array}{c}\text { \% share of } \\
\text { top 10\% }\end{array}$ & $\begin{array}{c}\text { Mean per } \\
\text { donor }(£)\end{array}$ & $\begin{array}{c}\text { Mean per } \\
\text { head }(£)\end{array}$ & $\begin{array}{c}\text { \% share of } \\
\text { top 10\% }\end{array}$ \\
\hline CAF/NCVO & 26.8 & 14.8 & 56 & 17.8 & 2.1 & 48 \\
Top coded & 31.2 & 17.7 & 62 & 23.1 & 2.3 & 61 \\
Original & 34.9 & 19.4 & 66 & 30.9 & 3.0 & 71
\end{tabular}

Note: surveys equally weighted.

\section{(ii) Giving to the Tsunami relief}

Donations to the appeal following the Asian Tsunami of December 2004 are not included in the figures for overseas giving in the paper. These donations were identified separately in the February 2005 Omnibus survey round (see Section 2); nearly a fifth of respondents reported giving in the previous four weeks, and twothirds reported a donation at some time since the Tsunami actually occurred. The latter accords reasonably well with a figure of 81 percent recorded in an NOP Omnibus quota sample of 1,000 people conducted between 14-16 January 2005 (CAF 2005). We do not consider giving to the Tsunami appeal in the paper on account of its exceptional nature. Nevertheless, it would be wrong to assume the Tsunami giving as completely separable. First, giving to other causes recorded in February 2005 may have been reduced as a consequence of donations to the Tsunami relief. Second, the experience of giving to the Tsunami appeal may have led some people to start making regular donations to overseas causes, or to give more often, or to give larger amounts.

Table A2 tries to shed some light on these issues. Overseas giving does not jump sharply upwards in the Omnibus data in the months following the Tsunami appeal. The frequencies of giving in June 2005 and February 2006 are effectively the same as in July 2004 and February 2005 respectively. The higher figures in October 2005 are likely to have been influenced by another exceptional event - the Pakistan earthquake appeal, which were not separately identified in the data. The Disasters Emergency Committee, an umbrella grouping of the main development charities, raised $£ 40$ million for the Pakistan earthquake appeal by mid-November 2005, which compares with $£ 300$ million for the Tsunami appeal (Disaster Emergencies 
Committee 2005). There is no significant difference between the means for domestic donations in February 2005 and in the other months taken together. The frequency of domestic giving in February 2005 is effectively the same as in February 2006. These results provide some justification for our exclusion of Tsunami giving from our analysis.

Table A2: Frequency of overseas and domestic giving and amounts given by donors by survey round

\begin{tabular}{rrrrr} 
& $\begin{array}{r}\text { Overseas } \\
\text { donor } \\
\%\end{array}$ & $\begin{array}{r}\text { Overseas } \\
\text { donor } \\
\text { mean }(£ s)\end{array}$ & $\begin{array}{r}\text { Domestic } \\
\text { donor } \\
\%\end{array}$ & $\begin{array}{r}\text { Domestic } \\
\text { donor } \\
\text { mean }(£ s)\end{array}$ \\
\hline Jul 2004 & 11.5 & 17.09 & 52.9 & 20.15 \\
Oct 2004 & 7.0 & 15.13 & 48.6 & 24.58 \\
Feb 2005 & 9.0 & 20.09 & 51.7 & 23.95 \\
Jun 2005 & 11.7 & 15.14 & 54.2 & 25.39 \\
Oct 2005 & 14.8 & 22.93 & 59.3 & 27.59 \\
Feb 2006 & 8.7 & 13.09 & 49.6 & 25.68
\end{tabular}

Note: the figures for the domestic means show the means of donations made to all domestic causes calculated across all persons making any domestic donations.

\section{iii) Frequency of giving by income quintile}

The Omnibus income data are sufficiently detailed to allow division of the sample (less persons not responding to the income question) into quintile groups of income. Figure A1 plots the percentages giving to overseas and domestic causes (taken together) separately for men and women and for married and single people. The quintile groups in each case refer to the distribution for the sample as a whole rather than the sub-group in question. 
Figure A1: Frequency of giving by income quintile: gender and marital status (\%)

a) Men

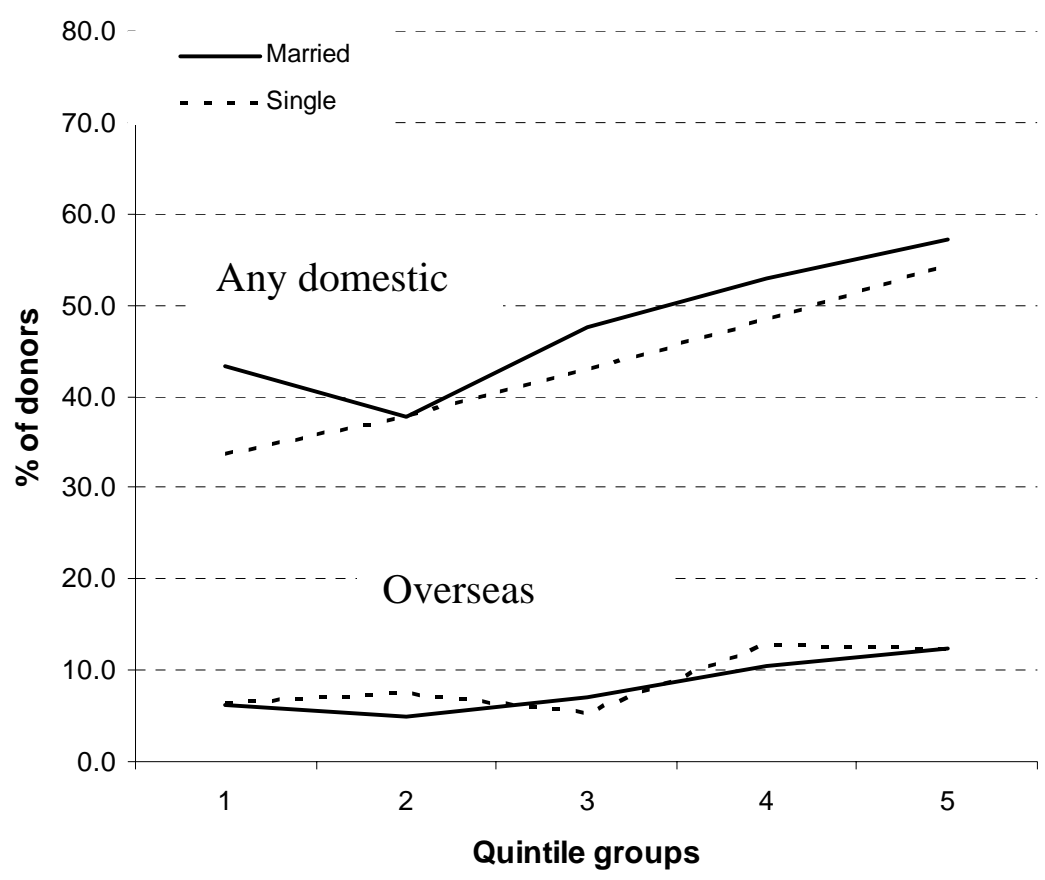

b) Women

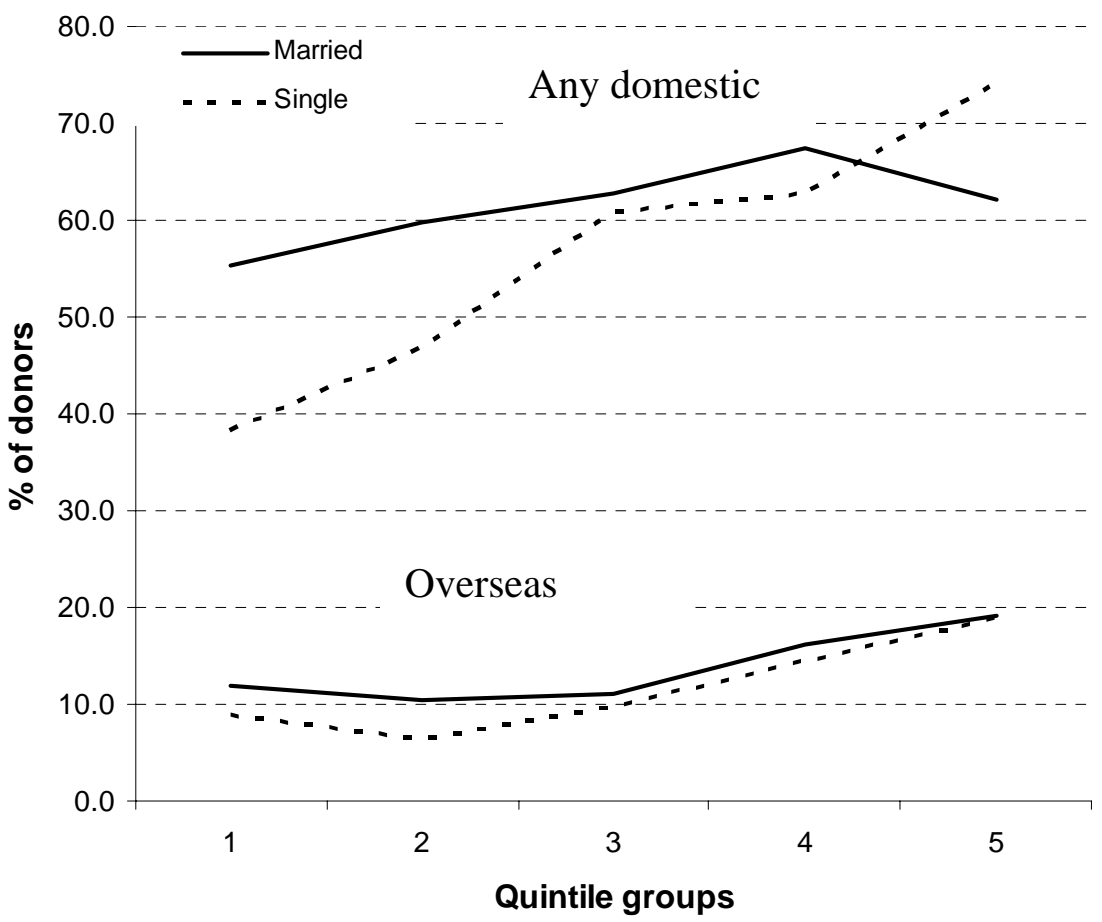




\section{$\underline{\text { References }}$}

Andreoni, J, Brown, E, Rischall I (2003) 'Charitable Giving by Married Couples:

Who Decides and Why Does it Matter? Journal of Human Resources, 38: 111-133.

Atkinson A. B. (2007) 'The Economics of Giving for Overseas Development', Unpublished paper, Nuffield College, Oxford.

Atkinson, R A and Eastwood A (2007) 'Public Attitudes to Overseas Giving: Does Government Make a Difference?’ Southampton Statistical Sciences Research Institute, Working Paper A07/05, University of Southampton.

Backus, P (2006) 'Is Charity a Homogenous Good? Variation in the Determinants and Motivations of Charitable Contributions across Causes', unpublished paper, Department of Economics, University of Warwick.

Banks J and S Tanner (1997), 'The State of Donation: Household Gifts to Charity, 1974-96', The Institute for Fiscal Studies, Commentary 62.

Breeze B (2006), 'Robin Hood in Reverse: Exploring the Relationship between Income and Charitable Giving', Voluntary Sector Working Paper 3, Centre for Civil Society, London School of Economics.

Charities Aid Foundation (2005) 'Record 81\% of adults gave to Tsunami appeals' http://www.fundraising.co.uk/news/4718

Charities Aid Foundation (2006) Charity Trends 2005, West Malling: Charities Aid Foundation

CAF and NCVO (2005) UK Giving 2004/05, West Malling: Charities Aid Foundation

CAF and NCVO (2006) UK Giving 2005/06, West Malling: Charities Aid Foundation

Disaster Emergencies Committee (2005) 'Generous Brits Make Asia Quake Dec's Third Biggest Appeal Ever’ http://www.dec.org.uk/index.cfm/asset_id,1462/pr,1

Havens J J, O’Herlihy, M A and Schervish P G (2006) 'Charitable Giving: How Much, by Whom, to What, and How?' in W P Powell and R Steinberg (eds.), The Non-Profit Sector: A Research Handbook, 2nd ed., New Haven and London: Yale University Press

HM Treasury (2004) 2004 'Spending Review: Press Notice (Section A9 Department for International Development)' available at http://www.hmtreasury.gov.uk/spending_review/spend_sr04/press/spend_sr04_press09.cfm

Jencks, C (1987) 'Who Gives to What?’ in W P Powell and R Steinberg (eds.), The Non-Profit Sector: A Research Handbook, 1st ed., New Haven and London: Yale University Press. 
Jones A M and Posnett J W (1991) 'Charitable donations by UK households: evidence from the Family Expenditure Survey’, Applied Economics, 23:343-51.

Jones, F (2006), 'The effects of taxes and benefits on household income, 2004-05', London: Office of National Statistics

http://www.statistics.gov.uk/cci/article.asp?id=1551

Lee N, P Halfpenny, A Jones and H Elliot (1995), 'Data Sources and Estimates of Charitable Giving in Britain’, Voluntas, 6(1):39-66.

Lloyd, T (2004) Why Rich People Give, London: Philanthropy UK.

Micklewright, J and Wright A (2004), 'Private Donations for International

Development' in A B Atkinson (ed.) New Sources of Development Finance, Oxford:

Oxford University Press.

Micklewright, J and Schnepf, S V (2007) 'How Reliable are Income Data Collected with a Single Question?’ Southampton Statistical Sciences Research Institute, Working Paper, forthcoming.

O’Brien, M (2004), Public Attitudes Towards Development, Social and Vital Statistics, Office for National Statistics, available from

http://www.dfid.gov.uk/pubs/files/omnibus2004.pdf

ONS (2007) 'The Omnibus Survey'

http://www.statistics.gov.uk/about/services/omnibus/default.asp, accessed 15.01.07.

Pharaoh C and S Tanner (1997), 'Trends in Charitable Giving', Fiscal Studies, 18(4): 427-443.

Piper G and S V Schnepf (2007), 'Gender Differences in Charitable Donations' Southampton Statistical Sciences Research Institute, Working Paper, forthcoming. 
Table 1: Frequency of giving in the four weeks prior to interview and average amounts per donor

\begin{tabular}{lccc} 
& $\begin{array}{c}\% \\
\text { giving }\end{array}$ & $\begin{array}{c}\text { mean } \\
\text { Es }\end{array}$ & $\begin{array}{c}\text { median } \\
\text { £s }\end{array}$ \\
\hline Medical research & 21.5 & 11.3 & 5.0 \\
Children or young people & 14.0 & 12.7 & 5.0 \\
Hospitals or hospices & 13.8 & 12.9 & 5.0 \\
Overseas aid and disaster relief & 10.4 & 17.8 & 9.0 \\
Animal welfare & 7.8 & 9.4 & 5.0 \\
Disabled people & 7.2 & 11.1 & 5.0 \\
Religious organisations & 6.6 & 35.3 & 12.0 \\
Other & 6.2 & 11.6 & 4.0 \\
Homeless people & 5.1 & 6.4 & 3.0 \\
Schools, colleges, universities etc & 4.7 & 12.0 & 5.0 \\
Elderly people & 4.3 & 8.3 & 5.0 \\
Physical and mental health care & 3.9 & 9.6 & 5.0 \\
Conservation, environment, heritage & 2.7 & 16.7 & 6.0 \\
Sports and recreation & 1.7 & 11.5 & 5.0 \\
Arts & 0.5 & 23.9 & 5.0 \\
& & & \\
All domestic causes & 52.7 & 24.6 & 10.0 \\
All causes & 55.4 & 26.8 & 10.0
\end{tabular}

Notes: Religious organizations include churches, mosques, and synagogues. Disabled people include the blind and the deaf. 'Other' include rescue services, human rights, benevolent funds, and refugees. Homeless people include housing and refuge shelters in the UK. Schools, colleges, universities include other education. 
Table 2: Distribution of amounts given

$\%$ of total given by:

\begin{tabular}{ccc}
$\begin{array}{c}\text { top 50\% of } \\
\text { donors }\end{array}$ & $\begin{array}{c}\text { top 10 \% of } \\
\text { donors }\end{array}$ & $\begin{array}{c}\text { Gini } \\
\text { coefficient }\end{array}$ \\
\hline 89 & 48 & 0.63 \\
85 & 51 & 0.63 \\
87 & 57 & 0.67 \\
82 & 38 & 0.55 \\
92 & 59 & 0.70 \\
89 & & \\
91 & 56 & 0.68 \\
& 56 & 0.69
\end{tabular}

Note: in each case the distribution is of positive amounts given. 
Table 3: Frequency of giving by cause, marital status and sex

\begin{tabular}{lrrrr} 
& \multicolumn{2}{c}{ Married } & \multicolumn{2}{c}{ Single } \\
& Men & Women & Men & Women \\
\hline Frequency of giving (\%): & & & & \\
$\quad$ All domestic & 50.9 & 59.5 & 41.9 & 52.5 \\
$\quad$ Overseas & 9.5 & 12.4 & 8.5 & 10.2 \\
Median per donor (£): & & & & \\
$\quad$ All domestic & 10.0 & 10.0 & 7.0 & 8.0 \\
$\quad$ Overseas & 10.0 & 8.0 & 5.0 & 6.2 \\
Mean per donor (£): & & & & \\
$\quad$ All domestic & 29.8 & 24.4 & 22.4 & 18.7 \\
$\quad$ Overseas & 19.5 & 20.5 & 12.7 & 13.0 \\
Mean per head (£): & & & & \\
$\quad$ All domestic & 15.2 & 14.5 & 9.4 & 9.8 \\
$\quad$ Overseas & 1.8 & 2.5 & 1.1 & 1.3
\end{tabular}

Notes: married includes co-habiting persons; single includes married people living apart. 
Table 4: Probability of giving to different causes by individual characteristics (\%)

\begin{tabular}{lrcccc} 
& overseas & $\begin{array}{c}\text { medical } \\
\text { research }\end{array}$ & children & animals & $\begin{array}{c}\text { domestic } \\
\text { (only) }\end{array}$ \\
\hline Manager / Professional & 16 & 24 & 18 & 8 & 49 \\
Routine / Manual workers & 7 & 19 & 12 & 8 & 43 \\
Degree & 19 & 24 & 19 & 8 & 45 \\
A level & 11 & 23 & 15 & 9 & 48 \\
O level / GCSE & 8 & 23 & 15 & 9 & 49 \\
No qualifications & 6 & 18 & 9 & 6 & 40 \\
Owns property & 12 & 24 & 15 & 9 & 48 \\
Dependent child in household & 13 & 23 & 20 & 8 & 48 \\
Age 60+ & 10 & 19 & 9 & 7 & 43 \\
Female & 12 & 24 & 16 & 9 & 48
\end{tabular}
All persons
10
22
14
8
45

Note: the final column refers to giving to just domestic causes. The 'owns property' category includes only actual home owners and not for example adult children living in a home owned by their parents. 
Table 5: the association between overseas and domestic giving

\begin{tabular}{|c|c|c|c|}
\hline \multirow{2}{*}{$\begin{array}{l}\text { Domestic } \\
\text { donor \% }\end{array}$} & \multicolumn{3}{|c|}{$\begin{array}{c}\text { Overseas } \\
\text { donor \% }\end{array}$} \\
\hline & No & Yes & Total \\
\hline No & 44.6 & 2.7 & 47.3 \\
\hline Yes & 45.0 & 7.7 & 52.7 \\
\hline Total & 89.6 & 10.4 & 100.0 \\
\hline
\end{tabular}

Note: the table classifies the pooled sample of 9,050 persons into domestic and overseas donors and shows the percentage of percentage in each combination. 
Table 6: Attitudes to poverty in developing counties and charitable giving, July 2004 (\%)

\begin{tabular}{lrrr} 
Degree of concern & $\begin{array}{r}\text { Overseas } \\
\text { donors }\end{array}$ & $\begin{array}{r}\text { Domestic } \\
\text { only }\end{array}$ & $\begin{array}{r}\text { Not a } \\
\text { donor }\end{array}$ \\
\hline very concerned & 42 & 26 & 24 \\
fairly concerned & 48 & 45 & 40 \\
no strong feelings on & 8 & 20 & 23 \\
not very concerned & 3 & 6 & 8 \\
not at all concerned & 0 & 3 & 5 \\
Total & & & \\
Sample size & 100 & 100 & 100 \\
& 194 & 741 & 705
\end{tabular}

Note: the table shows responses to the question 'Which item on this card best describes how you feel about levels of poverty in developing countries?'. Domestic donors are defined here to give only to domestic causes, while overseas donors include those also giving to domestic causes. Figure do not always sum to 100 due to rounding. 
Table 7: Probability of caring (all persons) and of giving to overseas (persons caring only) by individual characteristics (\%), July 2004

\section{Probability of caring Probability of giving} to overseas if caring

Manager / Professional

Routine and manual workers

75

Degree

67

A level

O level / GCSE

$75 \quad 14$

No qualifications

67

4

Owns property

65

10

Dependent child in household

71

10

Age 60+

68

17

Female

74

18

76

14

All persons

70

15 
Table 8: Methods by which people think they can contribute effectively to reducing poverty in developing countries (persons concerned about poverty only), July 2004

\begin{tabular}{lrrr} 
& $\begin{array}{r}\text { Overseas } \\
\text { donor }\end{array}$ & $\begin{array}{r}\text { Domestic } \\
\text { only }\end{array}$ & $\begin{array}{r}\text { Not a } \\
\text { donor }\end{array}$ \\
\hline Donating to charities & 80 & 67 & 60 \\
Buying fair trade goods & 51 & 53 & 45 \\
Pressure on politicians & 34 & 36 & 33 \\
Paying taxes & 28 & 34 & 38 \\
Supporting socially responsible business & 21 & 23 & 19 \\
Being involved in church & 19 & 16 & 13 \\
Work in developed countries & 18 & 14 & 17 \\
Traveling into the country as a tourist & 10 & 6 & 10 \\
Others & 2 & 0 & 1 \\
I cannot contribute effectively & 1 & 4 & 6
\end{tabular}

Sample size: 171 overseas donors, 536 domestic donors and 451 no donor, total number of people being very concerned 1,148. 
Table 9: Donations to domestic and overseas causes as a share of gross monthly personal income (\%)

\begin{tabular}{lccccc} 
Income group & $\begin{array}{c}\text { Married } \\
\text { men }\end{array}$ & $\begin{array}{c}\text { Married } \\
\text { women }\end{array}$ & $\begin{array}{c}\text { Single } \\
\text { men }\end{array}$ & $\begin{array}{c}\text { Single } \\
\text { women }\end{array}$ & $\begin{array}{c}\text { All } \\
\text { Persons }\end{array}$ \\
\hline Domestic: & & & & & \\
Bottom 80\% & 0.94 & 2.00 & 0.77 & 1.13 & 1.29 \\
Top 20\% & 0.67 & 0.80 & 0.82 & 0.91 & 0.73 \\
All & 0.76 & 1.51 & 0.80 & 1.06 & 0.99
\end{tabular}

Overseas:

Bottom 80\%

Top $20 \%$

0.12

0.38

0.09

0.14

0.20

All

0.09

0.10

0.09

0.15

0.09

0.27

0.09

0.14

0.14

Note: the income groups refer to the distributions of income among all persons. In order to estimate the denominator in these calculations we assign people to the midpoint of their income band in the Omnibus survey. Persons in the top unbounded range are assigned the mean in this range recorded for their gender in the 2004-5 Family Resources Survey (gender-specific means are not used in Figures 1 and 2). 
Table 10: Logistic regression models for probability of giving: coefficient of log income (single persons only)

\begin{tabular}{lccccc} 
& Domestic & Overseas & Animal & Medical & Children \\
\hline No controls & $0.437^{* *}$ & $0.524^{* *}$ & $0.159^{*}$ & $0.357^{* *}$ & $0.468^{* *}$ \\
included & $(0.062)$ & $(0.096)$ & $(0.079)$ & $(0.071)$ & $(0.080)$ \\
Controls & $0.391^{* *}$ & 0.187 & 0.147 & $0.415^{* *}$ & $0.438^{* *}$ \\
included & $(0.080)$ & $(0.115)$ & $(0.114)$ & $(0.092)$ & $(0.101)$
\end{tabular}

Note: robust standard errors in parentheses; * significant at 5\%; ** significant at $1 \%$. The models are estimated on single persons with annual income below $£ 2,600$ (which leads to $14 \%$ of single people being excluded); $n=3,378$ individuals. The first set of results are from models with no other variables included. The second set are from models including dummy variables for gender (female), property owner, manager/professional, routine/manual, degree, A-level and O-level or GCSE; 
Figure 1: Frequency of giving by level of monthly income (\%)

a) single persons

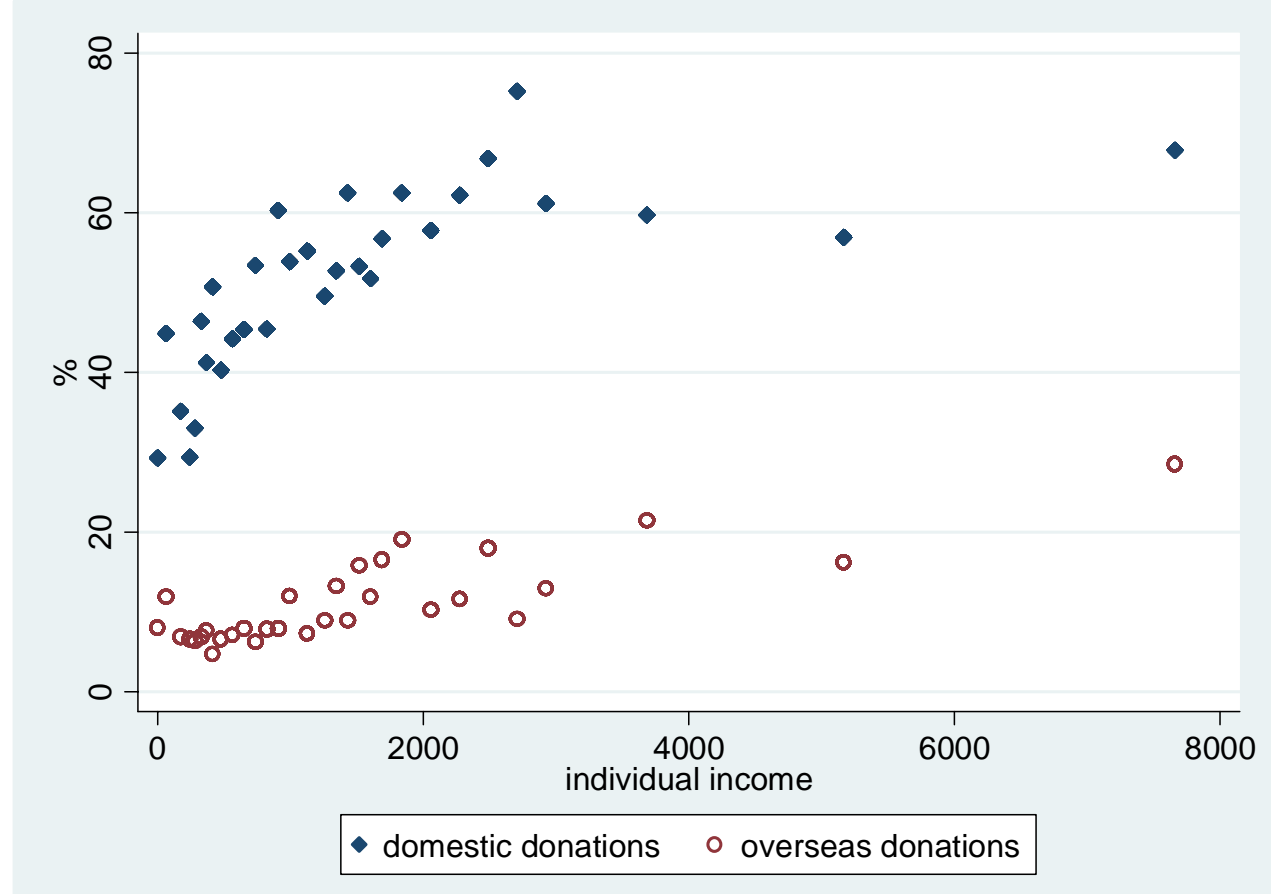

b) married persons

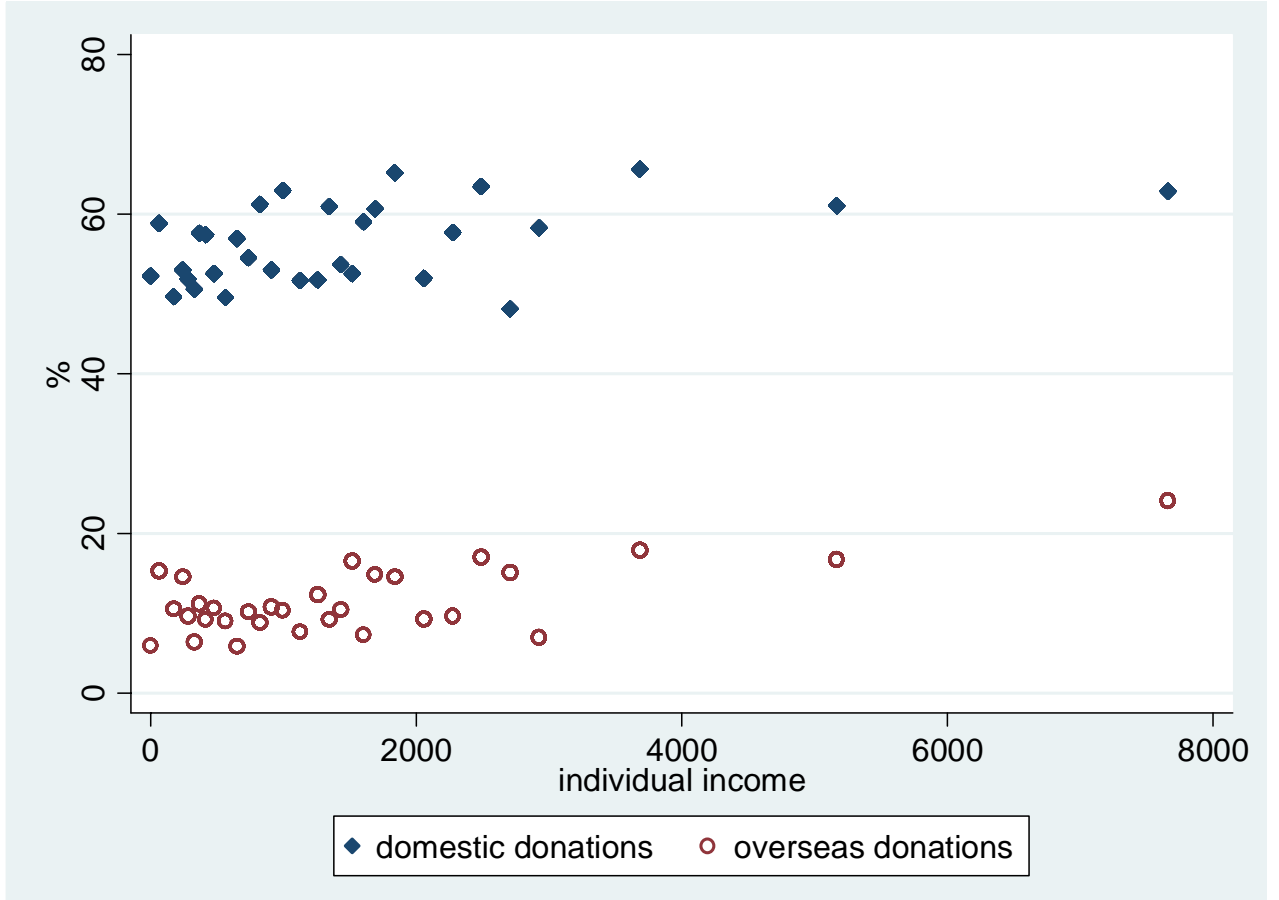

Note: the graphs show the percent giving in each income interval, plotted against the mid-point of the interval. 
Figure 2: Mean amount given per head by level of monthly income ( $($ )

a) single persons

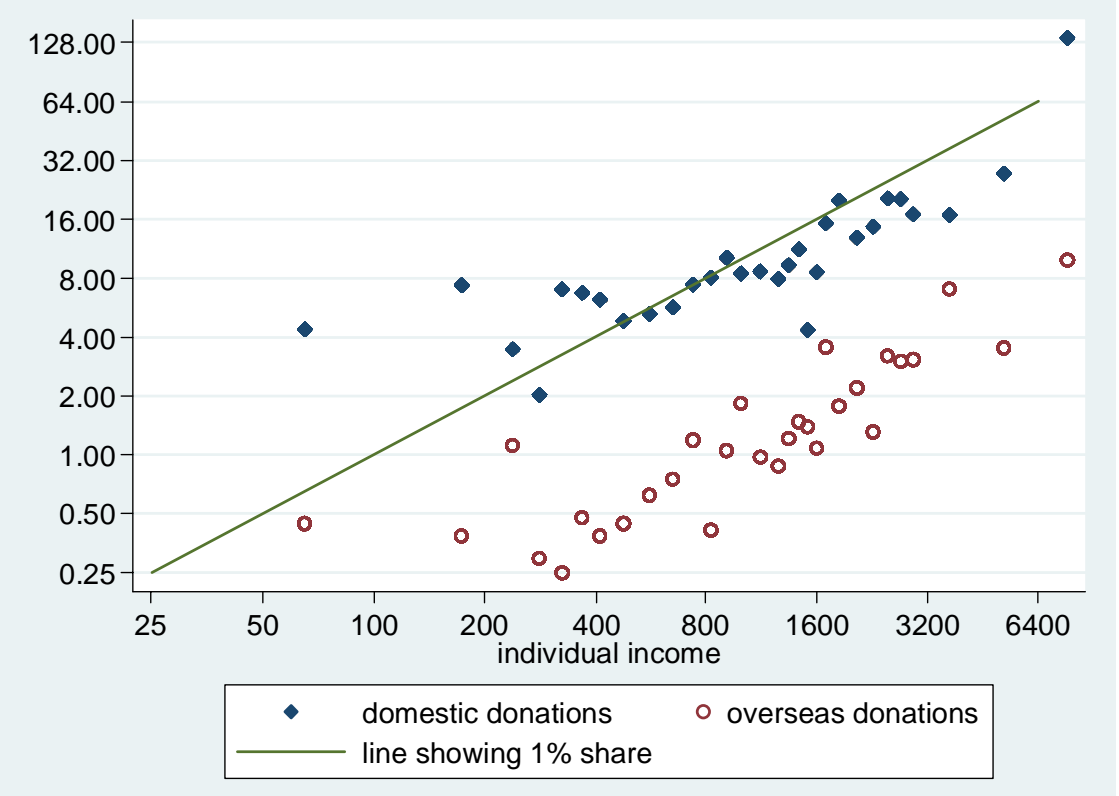

b) married persons

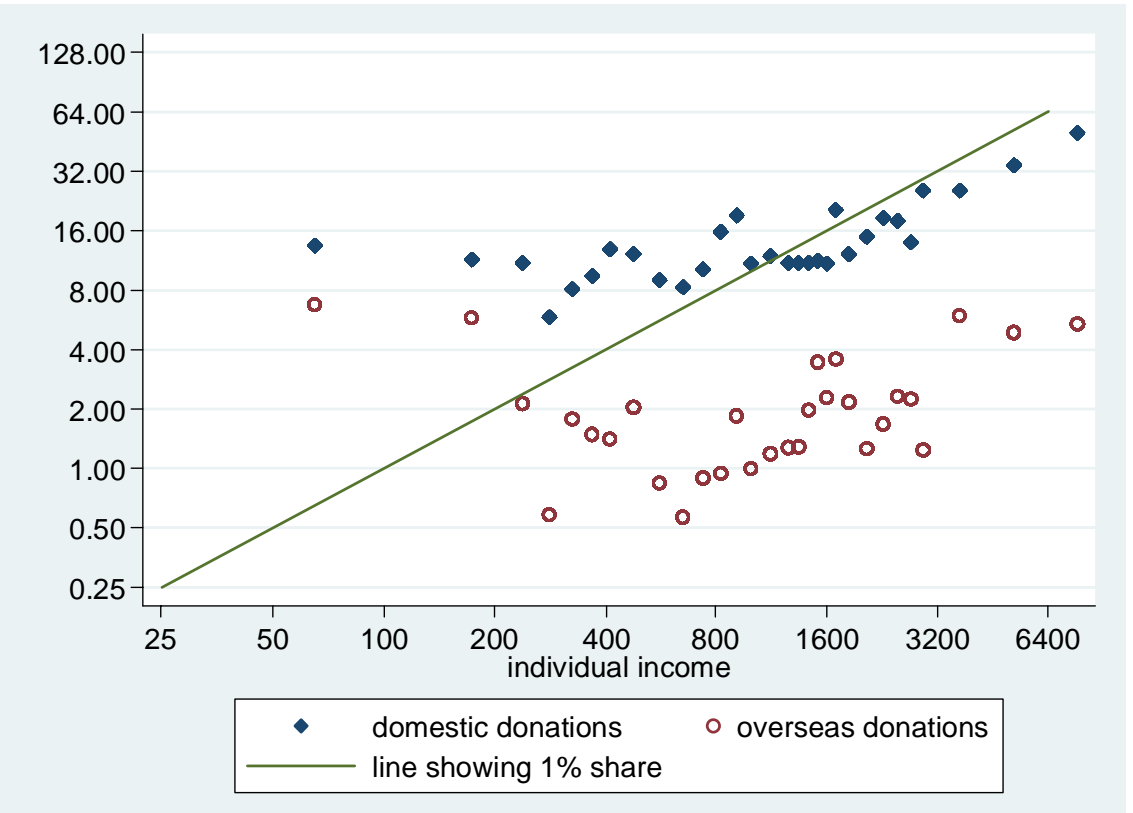

Note: the graphs plot the average amounts per head (averaging over donors and nondonors) by income level. People with zero income are excluded. See also footnote 19. 